\title{
Metodologia da Problematização: Reflexões acerca dA QUALIDADE DE VIDA COM ALUNOS UNIVERSITÁRIOS
}

\author{
PROBLEMATIZATION METHODOLOGY: REFLECTIONS ON THE QUALITY OF LIFE WITH \\ UNIVERSITY STUDENTS
}

METODOLOGÍA DE PROBLEMATIZACIÓN: REFLEXIONES SOBRE LA CALIDAD DE VIDA CON ESTUDIANTES UNIVERSITARIOS

\section{Fernanda Cristina Foss de \\ Zorzi \\ iD 9 \\ Doutoranda em Educação em \\ Ciências: Química da Vida e \\ Saúde (Unipampa) \\ fernandazorzi.aluno@unipampa.ed $\underline{\text { u.br }}$}

\section{Michele Bulhosa de Souza \\ iD 9 \\ Doutoranda em Educação em \\ Ciências: Química da Vida e \\ Saúde (Unipampa) \\ michelebulhosa@unipampa.edu.br}

\section{Sara Lima Pereira Correia iD 9}

Mestranda no Programa de

Ciências Fisiológicas (Unipampa) saralimacorrea2065@gmail.com

\section{Jaqueline Copetti}

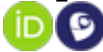

Doutora em Educação em

Ciências: Química da Vida e

Saúde (UFSM/RS)

Docente Permanente do Programa de Pós-graduação em Educação em Ciências: Química da Vida e

Saúde (Unipampa)

jaquelinecopetti@unipamapa.edu.b

\begin{abstract}
Resumo
Dentre os fatores implicados na aprendizagem de estudantes do Ensino Superior, pode-se destacar a qualidade de vida. O objetivo deste relato foi problematizar a qualidade de vida com alunos universitários por meio de aproximações da Metodologia da Problematização (MP) com o arco de Maguerez. As informações apresentadas de forma descritiva foram coletadas seguindo as etapas de desenvolvimento do arco e de questionário, antes e após a realização da oficina, sendo que, para a análise de tais informações, foi utilizada a análise temática. Como resultado, verificou-se a efetividade da utilização da MP como método didático-pedagógico para auxiliar os participantes na compreensão sobre sua qualidade de vida na percepção da necessidade de mudanças de comportamentos e atitudes para melhoria e manutenção dessa qualidade de vida. Em processos de ensino-aprendizagem, o uso da MP possibilita gerar o protagonismo do aluno do Ensino Superior quando alinhado à realidade dele.
\end{abstract}

Palavras-chave: Metodologia da Problematização. Ensino Superior. Protagonismo. Qualidade de vida.

Recebido em: 17 de maio de 2021.

Aprovado em: 15 de junho de 2021.

Como citar esse artigo (ABNT):

ZORZI, Fernanda Cristina Foss De. Metodologia da Problematização: reflexões acerca da qualidade de vida com alunos universitários. Revista Prática Docente, v. 6, n. 2, e046, 2021. http://doi.org/10.23926/RPD.2021.v6.n2.e046.id1173 


\begin{abstract}
Among the factors involved in the learning of higher education students, quality of life can be highlighted. The objective of this report was to problematize the quality of life with university students through approximations with the Problematization Methodology (PM) with the Maguerez arc. The information presented in a descriptive way was collected following the arch and questionnaire development stages before and after the workshop, and for the analysis of such information, thematic analysis was used. As a result, the effectiveness of using MP as a didactic-pedagogical method to help participants understand their quality of life was verified, in the perception of the need for changes in behavior and attitudes to improve and maintain this quality of life. In teaching-learning processes, the use of MP makes it possible to generate the leading role of higher education students when aligned with their reality.
\end{abstract}

Keywords: Questioning Methodology. University education. Protagonism. Quality of life.

\title{
Resumen
}

Entre los factores que intervienen en el aprendizaje de los estudiantes de educación superior, se destaca la calidad de vida. El objetivo de este informe fue problematizar la calidad de vida con estudiantes universitarios a través de aproximaciones con la Metodología de Problematización (PM) con el arco de Maguerez. La información presentada de manera descriptiva fue recolectada siguiendo las etapas de desarrollo del arco y cuestionario antes y después del taller, y para el análisis de dicha información se utilizó el análisis temático. Como resultado, se verificó la efectividad del uso de MP como método didáctico-pedagógico para ayudar a los participantes a comprender su calidad de vida, en la percepción de la necesidad de cambios de comportamiento y actitudes para mejorar y mantener esta calidad de vida. En los procesos de enseñanza-aprendizaje, el uso de MP permite generar el protagonismo de los estudiantes de educación superior cuando se alinea con su realidad.

Palabras clave: Metodología de cuestionamiento. Enseñanza Superior. Protagonismo. Calidad de Vida. 


\section{INTRODUÇÃO}

A qualidade de vida pode ser considerada uma das expressões mais debatidas em espaços sociais e nas políticas públicas, possuindo diversidade de definições. Ela é caracterizada como um aspecto intrinsecamente humano e ligado à percepção de cada indivíduo sobre sua vida e suas potencialidades, que possam gerar satisfação pessoal, profissional e social. A qualidade de vida possui relação tanto com os hábitos de vida quanto com fatores socioeconômicos que perfazem as condições de vida e da realidade de cada pessoa (LEITE, 2013; SOBRAL et al., 2015).

Na perspectiva de ingresso no Ensino Superior, os jovens deparam-se com um mundo novo e desconhecido, e esse é o momento de transição da adolescência para a vida adulta, quando ocorrem mudanças em sua rotina de estudos e nos laços afetivos, bem como há preocupação quanto ao futuro profissional. Além disso, para muitos, há adaptações quanto à moradia, à autonomia, ao gerenciamento do tempo, à mudança de convívio social devido ao distanciamento da família e amigos (NOGUEIRA-MARTINS, L.; NOGUEIRA-MARTINS, M., 2018).

De acordo com Lantyer et al. (2016, p. 16), o "ingresso no Ensino Superior exige recursos cognitivos e emocionais elaborados para o manejo das novas contingências impostas". Nesse sentido, os processos de ensino-aprendizagem desenvolvidos no Ensino Superior também podem ser fatores atribuídos à qualidade de vida, pois tais processos possibilitam aos envolvidos o protagonismo no processo de aprendizagem, e o uso desse para a vida cotidiana, ressignificando os conhecimentos aprendidos incorporados à sua vida pessoal, profissional e social (WYZYKOWSKI et al., 2020).

A Metodologia da Problematização (MP), com o uso do arco de Maguerez, pode ser aplicada como um método de ensino em pesquisas e em oficinas formativas para docentes e alunos (BERBEL; GAMBOA, 2012, BERBEL, 2014). Nesse caso, Pissaia et al. (2019) afirmam que o método do arco permite aos participantes a construção de situações de melhoria em seu contexto de vida e, ainda, instiga quem medeia a formação a sair da passividade, da transmissão de conhecimento e a motivar discussões, reflexões e construções.

Berbel (2012), por meio de seus estudos e pesquisas, apresenta três versões da MP com o uso do arco. A primeira versão está relacionada ao criador do arco, Charles Maguerez (19661970), cuja metodologia era voltada para a alfabetização e para a formação de trabalhadores em países subdesenvolvidos. Possuía um delineamento prioritariamente instrucional e centrado na 
transmissão de informação por parte dos instrutores e reprodução pelos aprendizes. Ações decisórias, reflexivas e críticas eram enfatizadas pelos instrutores, com pouco foco no aprendiz.

A segunda versão do arco está relacionada a sua adaptação, realizada por Bordenave e Pereira (1982/1988), que apresentaram alteração no esquema utilizado e com delineamento voltado à formação de professores. Já a terceira versão está relacionada a uma adaptação realizada por Berbel com base na versão de Bordenave e Pereira (1989), principalmente em relação ao método que agora é direcionado à práxis pedagógica, ao ensino-aprendizagem de alunos e à pesquisa. Nessa versão, a ênfase está na relação horizontal estabelecida entre professor e aluno. Assim, no trabalho ativo do aluno, que deve buscar aprender, e no professor, que assume o ponto central como orientador e mediador do processo, esse que requer clareza e coesão quanto à condução da aprendizagem (BERBEL, 2012). Vejamos abaixo o esquema do arco adaptado e utilizado por Berbel:

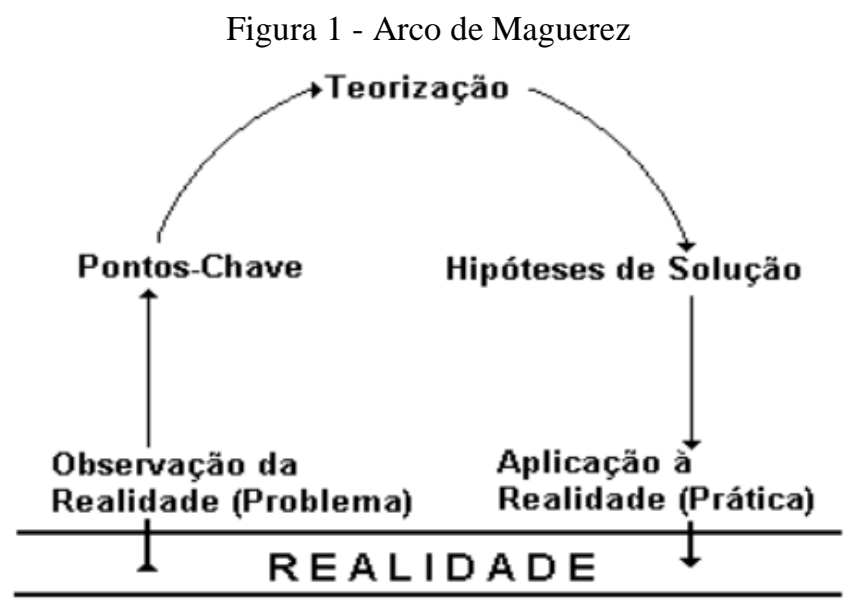

Fonte: Berbel (1998a; 1998b) adaptado de Bordenave e Pereira (1989)

As etapas do arco não se constituem sozinhas, elas têm interdependência e relação didático-pedagógica, partem da realidade e voltam para a realidade por meio da melhoria do contexto e de ações práticas. Dessa forma, o participante, seja professor, seja aluno, atua de maneira efetiva e construtiva, desenvolvendo o processo de ação-reflexão-ação. Nesse processo, tais atores constroem uma relação horizontal, colaborativa e evolutiva (BERBEL; GAMBOA, 2012).

Leão, Del Pino e Oliveira (2016, p. 105) afirmam que “[...] a educação desvinculada da realidade, pautada em formas tradicionais de ensino que priorizam a memorização, os resultados e o individualismo, desmotiva os estudantes por não apresentar atrativos e não responder a suas inquietações e necessidades”. Nesse sentido, é necessário ressignificar a 
prática de ensino-aprendizagem no contexto da Educação Superior e, com isso, abordar métodos didático-pedagógicos contextualizadores e problematizadores como, por exemplo, o uso de metodologias ativas (WYZYKOWSKI et al., 2020). Nesse contexto, o objetivo deste estudo foi problematizar a qualidade de vida com alunos universitários por meio de aproximações da MP com o uso do arco de Maguerez.

\section{Percurso metodológico}

Este estudo trata-se de um relato de experiência, com delineamento descritivo (Gil, 2007), de uma oficina sobre qualidade de vida, realizada com alunos do Ensino Superior. A oficina foi planejada e desenvolvida por meio de aproximações da MP com o uso do arco de Maguerez. Destaca-se o termo aproximações da MP com o uso do arco em decorrência de que a sua última etapa, a aplicação à realidade, não foi desenvolvida de forma integral, sendo elaborado apenas um plano de ação pelos alunos, no qual não foi possível a realização prática de implementação em função do tempo de execução da oficina. Dessa forma, entende-se que a MP com o uso do arco de Maguerez parte da realidade; e - após a realização de todo o percurso (etapas) - retorna à realidade, visando sua modificação, ou seja, de forma específica, busca a resolução do problema levantado. Sendo assim, conforme complementa Berbel, o uso do "arco de Maguerez, com o sentido especial de levar os alunos a exercitarem a cadeia dialética de açãoreflexão-ação, [...] tendo como ponto de partida e de chegada do processo de ensino e aprendizagem, a realidade social" (BERBEL, 1998, p.144).

A oficina foi realizada em um evento da área de Ciências Humanas, em uma Universidade Federal da Fronteira Oeste do Rio Grande do Sul, da qual participaram seis alunos e uma docente: dois alunos do curso de Jornalismo, dois alunos do curso de Serviço Social e dois alunos do curso de Relações Públicas. A docente participou da oficina, mas não respondeu ao questionário, ao final entregou anotações que fez durante a realização da oficina, possibilitando-nos fazer interpretações do desenvolvimento das etapas em que foi aplicada a MP com o uso do arco de Maguerez.

Ao iniciar a oficina, foi apresentado o Termo de Consentimento Livre e Esclarecido que foi assinado pelos participantes, seguindo como referência a resolução do CONEP 510/2016 para estudos com seres humanos. As informações apresentadas de forma descritiva neste relato foram coletadas antes (questionário), durante (etapas do arco de Maguerez) e após o desenvolvimento da oficina (questionário). 
Os participantes responderam a um questionário, com perguntas abertas, sobre o conhecimento prévio em relação à qualidade de vida. Após a realização da oficina, eles responderam a outras três questões sobre a concepção de qualidade de vida após participação na oficina; com base nas atividades desenvolvidas com a MP, com o arco de Maguerez, foi questionada a percepção sobre possíveis mudanças que poderiam realizar em suas vidas para terem mais qualidade de vida e bem-estar; bem como sugestões de ações que poderiam realizar para obter qualidade de vida no contexto da coletividade. A seguir são apresentadas as descrições das etapas do arco desenvolvidas na oficina:

$1^{\text {a }}$ etapa. Observação da realidade: neste momento, os participantes refletiram sobre a vida pessoal e acadêmica, também sobre os fatores que podem gerar ou não qualidade de vida. Após a reflexão, eles foram convidados a compartilhá-las.

$2^{\mathrm{a}}$ etapa. Pontos-chave: nesta etapa do arco, os participantes elencaram as condições ou situações que potencializam ou fragilizam a qualidade de vida e possíveis geradores de problemas pelos universitários.

$3^{\text {a }}$ etapa. Teorização: esta fase aconteceu por meio de explanação da abordagem teórica relacionada à temática da oficina, foram abordados conceitos de qualidade de vida voltados ao aspecto individual e coletivo, noção de bem-estar, dimensões da qualidade de vida e instrumentos de avaliação da qualidade de vida.

$4^{\mathrm{a}}$ etapa. Hipóteses de solução: foram resgatados os pontos-chave, e desses os considerados como potenciais causadores da qualidade de vida ou não. Foi proposto aos participantes que pensassem em aspectos ou ações que pudessem resolver tais situações.

$5^{\mathrm{a}}$ etapa. Aplicação à realidade: nesta última etapa, como forma de concretização das hipóteses de solução e aplicação delas na realidade do aluno, sugeriu-se que cada participante elaborasse um plano de ação para desenvolver em sua vida pessoal e acadêmica. Para construção do plano de ação, disponibilizou-se um quadro com seis colunas, sendo que, em cada uma, eles deveriam responder às perguntas: O quê? Por quê? Como? Para quem? Quando? Quem?

A análise das informações coletadas por meio dos questionários aconteceu com o uso de unidades temáticas sugeridas por Minayo (2009) e Bardin (2011). Utilizamos como base, na análise, a concepção dos participantes em seu aspecto individual, a qual é representada em quadros de resultados com uso de palavras-chave, como forma de significação. Com a intenção 
de garantir o anonimato, os participantes foram identificados com a letra $\mathrm{P}$ (Participantes) seguidos de numeral (P1 a P6).

\section{Resultados e Discussão}

Os resultados e a aplicação do questionário refletem as etapas do arco desenvolvidas durante a oficina. Tais etapas, planejadas e desenvolvidas com o fim de potencializar o processo de ensino-aprendizagem durante a atividade formativa. Nesse sentido, o quadro 1 retrata informações referentes à aplicação da questão inicial pré-oficina e que pode ser considerada como uma introdução à etapa 1 do arco, a observação da realidade:

Quadro 1 - Concepção inicial sobre qualidade de vida

\begin{tabular}{|l|l|}
\hline \multicolumn{1}{|c|}{ Palavras-chave } & \multicolumn{1}{c|}{ Respostas } \\
\hline Visão holística & $\begin{array}{l}\text { P2: [...] é proporcionar ao seu corpo, mente algo que procurava saúde; } \\
\text { P6: Equilíbrio entre saúde física, mental e emocional. }\end{array}$ \\
\hline Hábitos saudáveis & $\begin{array}{l}\text { P3: Ter hábitos saudáveis, praticar exercícios físicos, ter uma alimentação } \\
\text { equilibrada e procurar ter uma vida, rotina, mais saudável. }\end{array}$ \\
\hline Conhecimento & $\begin{array}{l}\text { P1: Conhecimentos básicos, conceitos rasos sobre o assunto, algumas ideias } \\
\text { equivocadas e outras nem tanto; }\end{array}$ \\
\hline Necessidades básicas & $\begin{array}{l}\text { P4: Onde todas as necessidades eram somadas como a alimentação, saneamento } \\
\text { básico de qualidade, relações sociais ativas, saúde física e mental impecável e } \\
\text { tudo isso em conjunto. }\end{array}$ \\
\hline
\end{tabular}

Fonte: informações coletadas por meio de questionários

O aspecto holístico foi relacionado à concepção de qualidade de vida, ou seja, a relação do indivíduo com o todo, na sua totalidade, que esse não pode ser separado e visto apenas como aspecto psicológico, biológico ou social. Anversa et al. (2018) realizaram um estudo com graduandos dos cursos de Terapia Ocupacional, Fonoaudiologia e Fisioterapia no qual objetivou comparar e refletir sobre a qualidade de vida de discentes do primeiro e do último ano de três cursos da área da saúde de uma Universidade Federal. Os resultados mostraram que os alunos do primeiro ano, dos referidos cursos, apresentaram menor qualidade de vida devido à fragilidade afetiva e social, exigências acadêmicas e frustrações, assim como a incerteza profissional. Já os alunos do último ano possuem uma melhor qualidade de vida, pois a permanência na universidade propicia amadurecimento e autonomia.

Outra concepção inicial dos participantes está relacionada ao entendimento de que qualidade de vida é desenvolver hábitos de vida saudável por meio de uma alimentação correta, exercícios físicos e estabelecer rotinas mais saudáveis. Martins G., Martins R. e Fiorese (2012), 
ao estudarem o nível de qualidade de vida e estilo de vida em universitários, referem que condições precárias de moradia, informação e comunicação, alimentação, atividade física e relacionamento interpessoal podem ser causadores ou potencializadores da falta de qualidade de vida do estudante. Tais autores relatam que os resultados da pesquisa voltados ao estilo de vida individual não foram considerados.

Quanto à referência em relação ao conhecimento, se por um lado os participantes revelam que possuem pouco ou que esse é limitante para o entendimento do que é qualidade de vida; por outro, identificam como um recurso que pode auxiliar na melhor condição de vida e, nesse sentido, a universidade pode auxiliar por meio de programas que instrumentalizam o aluno para a promoção da qualidade de vida. Viana e Sampaio (2019), ao desenvolverem estudo sobre a qualidade de vida de estudantes concluintes de cursos de graduação, referem que essa temática é importante frente aos diversos problemas que podem afetar o aluno, como, por exemplo, evasão de curso, dificuldades no desempenho cognitivo e outros aspectos relacionados à saúde e ao bem-estar do estudante. Ressaltam que pesquisas nessa área "podem servir de alerta, contribuindo para que gestores de universidades criem programas de promoção e prevenção que possam melhorar a qualidade de vida dos acadêmicos" (VIANA; SAMPAIO, 2019, p.1087).

Outro aspecto evidenciado pelos participantes foi o fato de a qualidade de vida ser uma necessidade básica, ou seja, podemos incluir como discussão as cinco necessidades básicas do indivíduo, até como questão motivacional: necessidade fisiológica, de segurança, social, estima e de autorrealização. Bampi et al. (2013) enfatizam que há dois critérios a serem considerados em relação à qualidade de vida, um individual e outro coletivo. O individual perfaz diversos setores da vida pessoal como, por exemplo, aspectos psicológicos, espirituais, ocupacionais e sociais. O segundo critério pensa a qualidade de vida no sentido coletivo, esse traduzido pelo acesso do indivíduo a aspectos como direitos humanos e direitos sociais, entre eles: a saúde, a educação, a segurança, o trabalho, o lazer, entre outros.

Por meio da problematização refletida nas etapas do arco que abrangem a observação da realidade, os pontos-chave e a teorização, pode-se perceber que, após a participação na oficina, houve uma ampliação da visão sobre a qualidade de vida dos participantes. O Quadro 2 apresenta os resultados relacionados às concepções pós-oficina: 
Quadro 2 - Concepções sobre qualidade de vida pós-oficina

\begin{tabular}{|l|l|}
\hline \multicolumn{1}{|c|}{ Palavras-chave } & \multicolumn{1}{c|}{ Respostas } \\
\hline Harmonia/ Equilíbrio & $\begin{array}{l}\text { P3: Qualidade de vida não é apenas os aspectos físicos relacionados } \\
\text { à alimentação e atividade física, mas sim algo mais profundo, mais } \\
\text { interior que atinge tanto o físico como principalmente o mental. }\end{array}$ \\
\hline Dúvidas/medos/inseguranças & $\begin{array}{l}\text { P1: [...] qualidade de vida nos afeta diariamente, seja ela em nossas } \\
\text { dúvidas, medos e insegurança [...]. }\end{array}$ \\
\hline Organização do tempo & $\begin{array}{l}\text { P2: É administrar melhor o tempo, priorizar coisas que façam a sua } \\
\text { vida melhor, é estabelecer um projeto de vida que faça com que o } \\
\text { corpo e a mente estejam em equilíbrio. }\end{array}$ \\
\hline Individualidade/ Singularidade & $\begin{array}{l}\text { P3: [...] seria uma junção de vários aspectos da vida que se } \\
\text { relacionam em harmonia e variando de indivíduo para indivíduo. }\end{array}$ \\
\hline
\end{tabular}

Fonte: informações coletadas por meio de questionários

Com a problematização gerada na oficina, os participantes passaram a perceber a qualidade de vida como um conjunto de ações que necessitam de harmonia/equilíbrio entre os aspectos biopsicossociais. O que vai ao encontro da definição de Alves et al. (2010) de que qualidade de vida é um conceito abrangente que envolve desde a saúde física, o psicológico, o nível de independência, as relações sociais e as relações com o meio ambiente no qual estamos inseridos.

Silva e Heleno (2012) realizaram um estudo com universitários no qual avaliaram a qualidade de vida e o bem-estar subjetivo. Os resultados mostraram que é necessário ter uma maior atenção à qualidade de vida dos estudantes, pois são muitos aspectos que interferem nela de forma negativa e que estão relacionados ao cotidiano agitado, à insegurança e às incertezas. Ingressar no Ensino Superior traz novas exigências para a vida dos jovens, são muitas demandas que, na maioria das vezes, acarretam em situações estressantes as quais prejudicam a qualidade de vida dos universitários (LOPES et al., 2019).

No estudo de Oliveira, Mininel e Fellil (2011), com alunos do curso de Enfermagem, ficou evidente que, para esses alunos, a percepção de qualidade de vida está entrelaçada com "poder fazer o que gostam" e "terem tempo para o trabalho e para vida pessoal (família, lazer e o cuidado de si)". Tais percepções vão ao encontro dos achados do presente estudo, já que os entrevistados sugerem que é necessário ter uma organização do tempo e citam até um "projeto de vida" para que haja mudanças na qualidade de vida. Paro e Bittencourt (2013), ao realizarem estudo com alunos de diferentes cursos da área da Saúde, demonstram que o cansaço e a falta de tempo livre têm forte relação com a qualidade de vida dos discentes. 
A qualidade de vida dos estudantes pode estar relacionada com o desempenho acadêmico. No estudo de Langame et al. (2016), o objetivo era caracterizar a qualidade de vida dos estudantes das áreas de Ciências Humanas, Exatas e Saúde, relacionando com o índice de rendimento acadêmico. Como resultado, ficou evidenciado que há um forte vínculo entre o rendimento e a qualidade de vida dos acadêmicos das respectivas áreas.

Qualidade de vida é uma abordagem complexa que envolve vários fatores, mas é considerada como a percepção do indivíduo em relação ao seu bem-estar, levando em consideração suas necessidades biopsicossociais e o contexto sociocultural de cada um (PEREIRA; TEIXEIRA; SANTOS, 2012). Ainda Brandão (2011) diz que qualidade de vida está relacionada ao bem-estar, sendo um conceito individualizado no qual cada pessoa tem a sua percepção do que é qualidade de vida.

No Quadro 3, os resultados referem-se às mudanças percebidas como necessárias pelos participantes para melhoria na sua qualidade de vida. Tais mudanças podem ser relacionadas às etapas do arco referentes às hipóteses de solução e aplicação à realidade, desenvolvidas na oficina, em que os alunos elaboraram e planejaram ações com impacto em sua vida pessoal e social:

Quadro 3 - Aplicação à realidade: mudanças individuais

\begin{tabular}{|l|l|}
\hline \multicolumn{1}{|c|}{ Palavras-chave } & \multicolumn{1}{c|}{ Respostas } \\
\hline Rotina/Planejamento & $\begin{array}{l}\text { P3: Ter mais planejamento na rotina, buscar o lado bom das coisas, entender } \\
\text { que a vida é feita de momentos bons e ruins e criar a sua própria concepção } \\
\text { de uma qualidade de vida melhor, estar buscando prioridades; }\end{array}$ \\
\hline Empatia & P5: Respeitar as diferenças, necessidades e momentos dos outros; \\
\hline Equilíbrio & $\begin{array}{l}\text { P3: Buscar trabalhar e se relacionar com equidade e principalmente } \\
\text { compreender que cada indivíduo é diferente do outro. }\end{array}$ \\
\hline Cuidado de si & $\begin{array}{l}\text { P6: Me preocupar mais comigo do que com os outros. Priorizar o meu } \\
\text { processo de amadurecimento e minha saúde mental. }\end{array}$ \\
\hline
\end{tabular}

Fonte: informações coletadas por meio de questionários

Ressalta-se que os participantes da oficina trazem a importância de planejar, estabelecer rotinas de exercício físico e lazer como estratégias de cuidado de si, pois "aquele que cuida de si, dos seus afazeres, das suas funções, [...] saberá manter as relações adequadas e prudentes para com seus entes próximos" (GOMES; FERRERI; LEMOS, 2018, p.195). A busca pelo equilíbrio remete ao reconhecimento da necessidade de organizar a rotina entre as atividades da vida universitária, família e trabalho (BARROS et al., 2017) e atividades que resultem em bem-estar físico, psíquico e espiritual. 
No que tange ao componente social da qualidade de vida, os participantes trazem a empatia como compreensão do outro, sendo que empatia caracteriza-se pela habilidade social de colocar-se no lugar do outro, perceber seus sentimentos e estar disponível para estar com o outro (TEREZAM; REIS-QUEIROZ; HOGA, 2017; BORDIN et al., 2019), sendo essa habilidade elencada pelos participantes como relevante na construção da qualidade de vida. Olhar o outro e perceber suas necessidades, e também voltar sua atenção ao ambiente e à sociedade remete ao pressuposto de que a busca pela qualidade de vida não depende apenas das ações individuais, mas também do coletivo (BAMPI et al., 2013).

É possível afirmar que o cuidado de si pode ser prejudicado pelo início da vida universitária, a qual pode configurar-se em um grande desafio de adaptação às novas exigências do mundo acadêmico. Ferreira et al. (2016, p. 60), em seu estudo, destacam que o "ingresso do estudante no Ensino Superior traz consigo uma gama de mudanças em nível pessoal, cognitivo, profissional, afetivo e social, além de acarretar uma série de expectativas em relação ao curso de graduação escolhido". Assim, Leão, Del Pino e Oliveira (2016, p.111) referem que:

Sabe-se que a inserção de novas metodologias pode ser um estímulo para a elevação
da autoestima dos educandos, fazendo com eles se sintam valorizados em aplicar os
conhecimentos adquiridos para melhoria de sua situação financeira e qualificação
profissional para disputar a concorrência do mundo do trabalho.

Com o uso do arco na realização da oficina, foi possibilitada aos alunos a discussão sobre seus contextos, bem como a criação de situações para modificá-los. O que refletiu na observação das modificações nas concepções iniciais dos participantes sobre a qualidade de vida quando comparadas às concepções após a oficina. Os participantes passaram a ter uma visão ampliada da qualidade de vida, e também refletiram a respeito de atitudes e de comportamentos necessários para a melhoria de sua qualidade de vida individual.

Cabe ressaltar, como limitações do estudo, o número de universitários participantes na oficina, a ausência de informações complementares referentes às atividades de trabalho e de atividades extra-acadêmicas e a pouca quantidade de publicação ou estudos sobre qualidade de vida na área dos cursos dos participantes: Relações Públicas, Jornalismo, Serviço Social, haja vista que a maioria dos estudos encontrados está direcionada aos estudantes da área da Saúde.

\section{CONSiderações Finais}

A experiência da utilização da MP com o arco de Maguerez para problematizar a qualidade de vida com estudantes universitários, na perspectiva de abranger o conhecimento individualizado, ou seja, no contexto da vida concreta de cada aluno, mostrou-se efetiva para 
promover a reflexão e a construção de estratégias para melhorar a qualidade de vida de forma individual e coletiva por meio do processo de ensino-aprendizagem contextualizado.

Em relação ao desenvolvimento da problematização com a aproximação do uso da MP e as etapas do arco de Maguerez, percebeu-se o envolvimento dos universitários quando refletiram sobre situações de suas vidas que poderiam favorecer ou dificultar sua qualidade de vida, bem como a participação desses acadêmicos na busca, de forma colaborativa, de soluções para si e para a coletividade em um contexto de Universidade, refletindo na potencialidade do bem-estar coletivo.

Como concepções pré-oficina, os participantes elencaram questões relacionadas à visão holística da qualidade de vida, às necessidades básicas e aos hábitos de vida. Já nas concepções pós-oficina, foram apontadas a busca pela harmonia e pelo equilíbrio na vida, a presença dos medos e das inseguranças, a individualidade e a possibilidade de organização do tempo. Com relação às mudanças que poderiam realizar em suas vidas para obter qualidade de vida, os participantes apontaram aspectos como: criar uma rotina por meio do planejamento, cuidar de si, ter empatia como forma de cuidar do outro, o que pode significar a percepção desses alunos quanto à falta da qualidade de vida em seu grupo de convivência, ou entorno social.

Verificou-se a relevância de atividades educativas, utilizando a MP com o arco de Maguerez, pela possibilidade do protagonismo gerado ao participante, possibilitando a ele olhar para a sua realidade concreta e visualizar a melhoria que pode desenvolver em seu contexto de vida, como benefício para si e para o outro. Dessa forma, há a necessidade de aprofundar estudos nesta temática, incluindo aqui, como perspectiva futura, a possibilidade de conhecer a realidade dos professores do Ensino Superior e as suas concepções e ou percepções sobre a qualidade de vida, além da abordagem dessa por meio de estratégias de ensino-aprendizagem problematizadoras, contextualizadoras e humanizadoras.

\section{REFERÊNCIAS}

ALVES, João Guilherme Bezerra; TENÓRIO, Manuela; ANJOS, Amanda Gomes dos; FIGUEIROA, José Natal. Qualidade de vida em estudantes de Medicina no início e final do curso: avaliação pelo Whoqol-bref. Revista Brasileira de Educação Médica, Rio de Janeiro, v.34, n.1, p. 91 - 96, 2010. Disponível em:

http://www.scielo.br/scielo.php?script=sci_arttext\&pid=S010055022010000100011\&lng=en\&nrm=iso. Acesso em: 01 jun. 2020.

ANVERSA, Andreisi Carbone; FILHA, Valdete Alves Valentins dos Santos; SILVA, Emilyn Borba da; FEDOSSE, Elenir. Qualidade de vida e o cotidiano acadêmico uma reflexão necessária. Cadernos Brasileiros Terapia Ocupacional., São Carlos, v. 26, n. 3, p. 626-631, 
2018. Disponível em: https://www.scielo.br/pdf/cadbto/v26n3/2526-8910-cadbto-26-0300626.pdf. Acesso em: 01 jun. 2020.

BAMPI, Luciana Neves da Silva; BARALDI, Solange; GUILHEM, Dirce; ARAÚJO, Marina Pereira de; CAMPOS , Ana Carolina de Oliveira. Qualidade de Vida de Estudantes de Medicina da Universidade de Brasília. Revista Brasileira de Educação Médica, Brasília, v.37, n. 2. p. 217-225, 2013. Disponível em: https://www.scielo.br/pdf/rbem/v37n2/09.pdf. Acesso em: 20 out. 2019.

BARDIN, Lawrence. Análise de conteúdo. São Paulo. Ed 70. 2011.

BARROS, Mariana Jordino de; BORSARI, Cristina Mendes Gigliotti; FERNANDES, Antonio de Olival; SILVA, Alexandre; FILONI, Eduardo. Avaliação da qualidade de vida de universitários da área da saúde. Revista Brasileira de Educação e Saúde, Pombal, v. 7, n. 1, p. 16, 2017. Disponível em:

https://www.gvaa.com.br/revista/index.php/REBES/article/view/4235/4244. Acesso em: 20 jul. 2020.

BERBEL, Neusi Aparecida Navas. A problematização e a aprendizagem baseada em problemas: diferentes termos ou diferentes caminhos? Interface - Comunicação, Saúde, Educação, v.2, n.2, 1998. Disponível em:

https://www.scielo.br/j/icse/a/BBqnRMcdxXyvNSY3YfztH9J/?lang=pt\&format=pdf Acesso em: 08 jun. 2021.

BERBEL, Neusi Aparecida Navas. A Metodologia da Problematização com o Arco de Maguerez uma reflexão teórico-epistemológica. Eduel, 2012.

BERBEL, Neusi Aparecida Navas. Metodologia da problematização: respostas de lições extraídas da prática. Semina: Ciências Sociais e Humanas, Londrina, v. 35, n. 2, p. 61-76, 2014. Disponível em: http://www.uel.br/revistas/uel/index.php/seminasoc/article/view/18193. Acesso em: 10 out. 2019.

BERBEL, Neusi Aparecida Navas; GAMBOA, Sílvio Ancízar Sánchez. A Metodologia da Problematização com o Arco de Maguerez uma reflexão teórico-epistemológica. Filosofia e Educação, V.3, N. 2, 2012. Disponível em:

https://periodicos.sbu.unicamp.br/ojs/index.php/rfe/article/view/8635462/3255. Acesso em: 10 out. 2019.

BORDENAVE, Juan Diaz; PEREIRA, Adair Martins. Estratégias de ensino aprendizagem. 4. ed. Petrópolis: Vozes, 1989

BRASIL, Resolução n ${ }^{\circ}$ 510, de 07 de abril de 2016. Dispõe sobre as normas aplicáveis a pesquisas em Ciências Humanas e Sociais cujos procedimentos metodológicos envolvam a utilização de dados diretamente obtidos com os participantes ou de informações identificáveis ou que possam acarretar riscos maiores do que os existentes na vida cotidiana. Brasília, DF: CONEP. Disponível em: http://conselho.saude.gov.br/resolucoes/2016/Reso510.pdf. Acesso em: 01 jun. 2020.

BORDIN, Danielle; VASCOSKI, Vivian Carla.; PEREIRA, Álex Renan Gonçalves; SANTOS, Celso Bilynkievycz dos; ZANESCO, Camila; FADEL, Cristina Berger. Relação 
entre empatia e qualidade de vida: um estudo com profissionais da Atenção Primária à Saúde. REME - Revista Mineira de Enfermagem n. 23, p.1-7 e-1253, 2019. Disponível em: https://cdn.publisher.gn1.link/reme.org.br/pdf/e1253.pdf. Acesso em: 01 jun. 2020.

BRANDÃO, Helena. Percepção corporal e qualidade de vida individual. Lifestyle Journal, v.1, n. 1, p11-13, 2011. Disponível em:

http://acta.nisled.org/index.php/LifestyleJournal/article/view/4. Acesso em: 11 ago. 2020.

FERREIRA, Michelle; CORTEZ, Elaine Antunes; SILVA, Jorge Luiz Lima da; FERREIRA, Maylu Júlio. Avaliação da saúde mental positiva de discentes de enfermagem. Revista Portuguesa de Enfermagem de Saúde Mental, Porto, n. 4, p. 57-62, 2016. Disponível em: http://www.scielo.mec.pt/scielo.php?script=sci_arttext\&pid=S1647-

21602016000400009\&lng=pt\&nrm=iso. Acessos em: 17 ago. 2020.

GIL, Antonio Carlos. Métodos e Técnicas de Pesquisa Social. 5 ed. São Paulo: Atlas, 2007.

GOMES, Marcel Maia.; FERRERI, Marcelo; LEMOS, Flávia. O cuidado de si em Michel Foucault: um dispositivo de problematização do político no contemporâneo. Fractal, Rev. Psicol., Rio de Janeiro, v. 30, n. 2, p. 189-195, 2018. Disponível em: https://periodicos.uff.br/fractal/article/view/5540 . Acesso em: 10 jul. 2020.

LANGAME, Angélica de Paula; NETO, José Antônio Chehuen; MELO, Luisa Normandia Baeta; CASTELANO, Mikaela Luana; CUNHA, Moarmedi; FERREIRA, Renato Erothildes. Qualidade de vida do estudante universitário e o rendimento acadêmico. Revista Brasileira Promoção e Saúde, Fortaleza, v. 29, n. 3, p. 313-325, 2016. Disponível em: https://periodicos.unifor.br/RBPS/article/view/4796. Acesso em: 01 jul. 2020.

LANTYER, Angélica da Silva; VARANDA, Caroline Ciardi; SOUZA, Felipe Granado de; PADOVANI, Ricardo da Costa, VIANA; Milena de Barros . Ansiedade e Qualidade de Vida entre Estudantes Universitários Ingressantes: Avaliação e Intervenção. Rev. Bras. de Ter. Comp. Cogn., v. 9, n. 2, p. 4-19, 2016. Disponível em: http://www.usp.br/rbtcc/index.php/RBTCC/article/view/880/476. Acesso em: 17 ago. 2020.

LEÃO, Marcelo; DEL PINO, José Claudio; OLIVEIRA, Eniz Conceição. Reflexões teóricas sobre as metodologias de ensino voltadas ao atendimento das especificidades da educação de jovens e adultos. Revista Prática Docente. v. 1, n. 1, p. 104-115, 2016. Disponível em: http://periodicos.cfs.ifmt.edu.br/periodicos/index.php/rpd/article/view/19/14. Acesso em: 15 mar. 2021.

LEITE, Pollyanna Nayara. Qualidade de vida e Promoção da Saúde. Id. on line Revista de Psicologia. Ano 7, n. 20, p: 33-56, 2013. Disponível em: https://idonline.emnuvens.com.br/id/article/view/235/260. Acesso em: 19 abr. 2021.

LOPES, Letícia de Sousa; FREITAS, Laynna Martins de Souza Modesto de; ALVES, Sueli Maria; MEDEIROS, Mauro Osvaldo. estudo sobre a qualidade de vida dos estudantes da Universidade Federal de Rondonópolis, MT utilizando dados comportamentais.

Biodiversidade, n.18, v.2, P. 28- 47, 2019. Disponível em: https://periodicoscientificos.ufmt.br/ojs/index.php/biodiversidade/article/view/8694. Acesso em: 17 ago. 2020. 
MARTINS, Guilherme Henrique; MARTINS, Roseli de Souza; FIORESE, Maria Eloiza. Análise dos parâmetros de qualidade e estilo de vida de universitários. Revista Mackenzie de Educação Física e Esporte, v. 11, n. 1, p. 22-30, 2012. Disponível em:

http://editorarevistas.mackenzie.br/index.php/remef/article/view/3293. Acesso em: 20 jul. 2020.

MINAYO, Maria Cecília de Souza. Pesquisa social: teoria, método e criatividade. 28 ed. Petrópolis, RJ. 2009.

NOGUEIRA - MARTINS, Luiz Antonio; NOGUEIRA - MARTINS, Maria Cezira Fantini . Saúde Mental e Qualidade de Vida de estudantes universitários. Revista Psicologia, Diversidade e Saúde, v. 7, n. 3, p. 334-337, 2018. Disponível em: https://www5.bahiana.edu.br/index.php/psicologia/article/view/2086/2119. Acesso em: 17 ago. 2020.

OLIVEIRA, Beatriz Marques de; MININEL, Vivian Aline; FELLIL, Vanda Elisa Andres. Qualidade de vida de graduandos de enfermagem. Revista Brasileira de Enfermagem, Brasília, v. 64, n.1, p. 130-135, 2011. Disponível em: https://www.scielo.br/pdf/reben/v64n1/v64n1a19.pdf. Acesso em: 01 jun. 2020.

PARO, César Augusto; BITTENCOURT, Zélia Zilda Lourenço de Camargo. Qualidade de vida de graduandos da área da saúde. Rev. Brasileira de Educação Médica, Campinas, v. 37, n. 3, p. 365-375, 2013. Disponível em: https://www.scielo.br/pdf/rbem/v37n3/09.pdf. Acesso em: 01 jun. 2020.

PEREIRA, Érico Felden; TEIXEIRA, Clarissa Stefani, SANTOS, Anderlei dos. Qualidade de vida: abordagens, conceitos e avaliação. Rev. Bras. Educ. Fís. Esporte, São Paulo, v.26, n.2, p.241-50, 2012. Disponível em: https://www.scielo.br/pdf/rbefe/v26n2/07.pdf. Acesso em: 01 jun. 2020.

PISSAIA, Luís Felipe; REHFELDT, Márcia Jussara Hepp; COSTA, Arlete Eli Kunz da; MOCCELIN, Jéssica Maria; MONTEIRO, Sabrina. Contribuições da metodologia da problematização na formação de cuidadores de idosos. Ensino, Saúde e Ambiente, v.12, n.1, p. 143-159, 2019. Disponível em:

https://periodicos.uff.br/ensinosaudeambiente/article/view/21538/16622. Acesso em: 01 jun. 2020.

SILVA, Érika Correia; HELENO, Maria Geralda Viana. Qualidade de Vida e Bem-Estar Subjetivo de Estudantes Universitários. Revista Psicologia e Saúde, v. 4, n. 1, p. 69- 76, 2012. Disponível em: https://www.pssa.ucdb.br/pssa/article/view/126. Acesso em: 01 jun. 2020.

SOBRAL, Mirely Eunice; GONTIJO, Daniela Tavares; ABDALA, Dennis William; CABRAL, Thamiris Nascimento. Avaliação da qualidade de vida de adolescentes em situação de vulnerabilidade social. Rev. Bras. Promoção Saúde, Fortaleza, v. 28, n 4: p. 568-577, 2015. Disponível em: https://periodicos.unifor.br/RBPS/article/view/3886. Acesso em: 19 abr. 2021.

TEREZAM, Raquel; REIS- QUEIROZ, Jessica; HOGA, Luiza Akiko Komura. A importância da empatia no cuidado em saúde e Enfermagem. Rev. Bras. Enferm. v. 70, n,3, p. 669-70, 
2017. Disponível em: https://www.redalyc.org/pdf/2670/267051078031_5.pdf. Acesso em: 17 ago. 2020.

WYZYKOWSKI, Tamini; KESKE, Cátia; RIGODANZO, Sirlei; NEHRING, Cátia Maria; PANSERA- DE- ARAÚJO, Maria Cristina. Compreensões sobre a atividade de ensino na educação superior. Revista Prática Docente. v. 5, n. 3, p. 1980-1998, 2020. Disponível em: http://periodicos.cfs.ifmt.edu.br/periodicos/index.php/rpd/article/view/904/419. Acesso em: 15 mar. 2021.

VIANA, Aiala Galvão; SAMPAIO, Leonardo. Qualidade de Vida dos Universitários em período de Conclusão de Curso. Id on Line Revista Multidisciplinar e de Psicologia. v.13, n. 47 p. 1085-1096, 2019. Disponível em:

https://idonline.emnuvens.com.br/id/article/viewFile/2106/3155. Acesso em: 20 jul. 2020. 